\title{
Nathalie Grande, Le Rire galant. Usages du comique dans les fictions narratives de la seconde moitié du XVII siècle
}

\section{Chiara Mainardi}

\section{(2) OpenEdition}

\section{Journals}

\section{Edizione digitale}

URL: https://journals.openedition.org/studifrancesi/4666

DOI: $10.4000 /$ studifrancesi.4666

ISSN: 2421-5856

\section{Editore}

Rosenberg \& Sellier

\section{Edizione cartacea}

Data di pubblicazione: 1 avril 2012

Paginazione: 140-141

ISSN: 0039-2944

\section{Notizia bibliografica digitale}

Chiara Mainardi, «Nathalie Grande, Le Rire galant. Usages du comique dans les fictions narratives de la seconde moitié du xvII e siècle», Studi Francesi [Online], 166 (I | LVI) | 2012, online dal 30 novembre 2015, consultato il 19 novembre 2021. URL: http://journals.openedition.org/studifrancesi/4666 ; DOI: https:// doi.org/10.4000/studifrancesi.4666

Questo documento è stato generato automaticamente il 19 novembre 2021.

\section{(c) $(1) \odot$}

Studi Francesi è distribuita con Licenza Creative Commons Attribuzione - Non commerciale - Non opere derivate 4.0 Internazionale. 


\title{
Nathalie Grande, Le Rire galant. Usages du comique dans les fictions narratives de la seconde moitié du XVII siècle
}

\author{
Chiara Mainardi
}

\section{NOTIZIA}

NATHALIE GRANDE, Le Rire galant. Usages du comique dans les fictions narratives de la seconde moitié du XVII siècle, Paris, Honoré Champion, 2011, pp. 332.

1 Attraverso l'esplorazione degli usi del comico, Nathalie Grande contribuisce a definire l'estetica della galanteria nelle finzioni narrative in prosa della seconda metà del XVII secolo. Evidenziando la continuità che si delinea tra il XVII e il xvIII secolo, sia sul piano letterario che su quello delle idee, l'A. tenta di correggere l'immagine del Grand Siècle troppo spesso appiattita sull'estetica del classicismo. Da un lato l'A. riesamina la funzione liberatoria del riso e del sorriso, dall'altro contribuisce alla definizione della nozione di comico galante, dando risalto ad alcune aree finora inesplorate della finzione narrativa. Allargando la nozione di 'comico' alle forme di divertimento intellettuale e di ironia, l'A. analizza le forme della comicità allorquando questa subisce l'influenza della galanteria, concetto in formazione nella seconda metà del secolo. Il rire galant, che utilizza il ridicolo e la satira, trasgredendo le bienséances, si ritrova in un corpus letterario costituito da narrazioni ludiche, aneddoti piccanti, trasgressivi, mistificazioni letterarie e novelle comico-galanti. Nel volume si confrontano le innovazioni introdotte dall'estetica galante nelle tradizioni ereditate dal comico attraverso lo studio del travestimento, del registro comico volgare e della licenziosità clericale. L'Histoire amoureuse des Gaules di Bussy, Le Portefeuille di Mme de Villedieu, L'Héroïne mousquetaire di Préhac, Vénus dans le cloître dell'Abbé du Prat, e La Princesse de 
Clèves di Mme de Lafayette sono alcune delle letture che l'A. privilegia in questo suo progetto. L' A. pone due limiti cronologici alla sua ricerca: Les Nouvelles françaises (1656) di segrais come terminus a quo e le Histoires ou contes du temps passé (1697) di Perrault come terminus ad quem. Il volume si suddivide in tre parti: la prima tratta la ricerca dell'enjouement galante nelle finzioni narrative, la seconda il passaggio dalla galanteria al libertinaggio, con i piaceri della trasgressione, l'ultima affronta le finzioni sovversive della satira politica. Un interessante epilogo propone una nuova lettura della Princesse de Clèves che, evidenziando elementi parodistici e satirici interni all'opera, lascia la porta aperta ad una lettura enigmatica e ironica del testo stesso.

2 Si segnala che nel capitolo consacrato alle finzioni anticlericali e antireligiose, l'autrice afferma in nota che l'attribuzione dell'opera Vénus dans le cloitre a Chauvigny de la Bretonnière, anziché all'Abbé du Prat, necessiterebbe di un esame approfondito, ma non fa alcun riferimento all'edizione critica di Jean sgard (2009), che abbiamo già recensito in questa rassegna (n. 164) e che analizza il problema nell'introduzione al testo. Molto curata è la bibliografia dell'opera, suddivisa in fonti e studi critici. 